\title{
VIRGILIO Y LAS HEROÍNAS GRIEGAS: PARALELISMOS EN LA CONSTRUCCIÓN DE DOS FIGURAS MÍTICAS
}

\author{
RAMIRO GONZÁLEZ DELGADO *
}

\begin{abstract}
Este artículo pretende mostrar cómo Virgilio innova en el tratamiento mítico de Eurídice, la mujer de Orfeo, y Creúsa, esposa de Eneas. El poeta mantuano asienta la versión canónica de éstas para la posteridad, asimilando las dos figuras míticas (a partir de evocadoras imágenes y recursos estilísticos) en virtud de una primitiva homonimia entre sus nombres.
\end{abstract}

Palabras clave: Literatura latina. Literatura comparada. Intertextualidad. Mitología clásica.

\begin{abstract}
This article is aimed to show how Virgil introduces new elements in Eurydice (Orpheus' wife) and Creusa's (Aeneas' wife) myths. The Mantuan poet sets up the canonical versions of these Greek heroines for the future and assimilates the two mythical characters thanks to an old homonym among their names.

Key-words: Latin Literature. Comparative Literature. Intertextuality. Classical Mythology.
\end{abstract}

Si atendemos a la tradición mitológica tal y como nos ha llegado hoy, no vemos ningún punto de contacto entre dos heroínas míticas aparentemente bien conocidas: Eurídice, esposa de Orfeo, y Creúsa, esposa de Eneas.

La primera aparece vinculada al mito de Orfeo y, más en concreto, al mitema de la catábasis órfica: tras la muerte de su esposa, el héroe tracio, gracias a los sones de su lira, consigue descender al mundo de los muertos en su busca. Cautiva a los dioses infernales y consigue de ellos la recuperación de su amada con la condición de no mirar hacia atrás hasta no haber salido de las moradas infernales. Pero en el último instante Orfeo se vuelve y pierde a su amada. Vanos serán los nuevos intentos por recuperarla. El héroe se queda triste y solo, manteniéndose fiel al recuerdo de su amada. Las mujeres tracias, sintiéndose ofendidas porque Orfeo no les hacía ningún caso, lo despedazan durante un ritual báquico.

\footnotetext{
* E-mail: ramiro@correo.uniovi.es. Trabajo subvencionado por el II Plan Regional de Investigación del Principado de Asturias.
} 
La segunda es la hija de Príamo y Hécuba, reyes de Troya. Es, además, la esposa de Eneas, el héroe troyano que consigue escapar de Ilión la fatídica noche de la destrucción con su padre Anquises sobre los hombros y su hijo. Creúsa había sido raptada por Afrodita y su esposo la busca. Eneas vuelve a Troya para encontrarla y se le aparece su sombra que le predice sus viajes en pos de una nueva patria.

Para saber algo de estas dos heroínas griegas debemos recurrir a la obra del poeta romano por excelencia: Virgilio. Así, leemos en Georg. IV 453527 y en Aen. II 736-804, la historia de estas dos mujeres. Será el autor de Mantua quien dé forma y figura a estas dos heroínas para la posteridad.

Ya se ha señalado que, en los relatos míticos, las mujeres y sus nombres no aparecen con la misma precisión que los héroes masculinos. En estos aspectos se ha detenido D. Lyons ${ }^{1}$ que señala que muchos personajes míticos femeninos figuran con nombres diversos según las versiones. Las dos heroínas ante las que estamos son una buena prueba de ello. Eurídice es nombrada en la obra del poeta elegíaco helenístico Hermesianacte (frag. 7 Powell, v. 2) como Argíope y, por lo que se refiere a Creúsa, como luego veremos, no era conocida en principio por este nombre. Es más, siempre que aparecen en las obras de la literatura griega, especialmente arcaica y clásica, las referencias que encontramos a ellas son "hija de", "esposa de", "madre de", sin llegar a tener una verdadera autonomía ${ }^{2}$. En cierto modo, es una manera de decirnos que el nombre de estas mujeres carece de importancia. Los nombres "Eurídice" y "Creúsa" son cotidianos y habituales en el imaginario y en el mundo griego. Si en los textos literarios no tenemos los nombres de nuestras mujeres, esto significa que no tienen historia. Posteriormente, cuando el nombre entra a formar parte del mito literario, presentan homonimia con el de otras heroínas.

Me he detenido en el personaje de Eurídice en un trabajo anterior ${ }^{3}$. En él había recopilado trece personajes mitológicos bajo este mismo nombre. Con Creúsa sucede lo mismo pero en una cantidad menor. En el mundo clásico

1 D. Lyons, Gender and Immortality. Heroines in Ancient Greek Myth and Cult, New Jersey 1997, pp. 51-58.

2 Así, por ejemplo, en el caso de la esposa de Orfeo, Platón (Symp. 179 d) prefiere toda

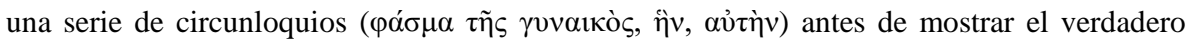
nombre de la protagonista.

3 R. González Delgado, «Eurídice: moritura puella», Actas del X Congreso Español de Estudios Clásicos. Vol. I, Madrid, 2000, pp. 445-451. 
aparecen seis personajes diferentes con este nombre, cinco mitológicos y uno histórico: la esposa del arcadio Casandro, según Quinto de Esmirna, VIII 82. Entre los personajes de la mitología se encuentran: una náyade tesalia hija de Gea y amada por el dios Peneo; la hija de Erecteo y Praxitea; la hija del rey corinto Creonte; el nombre de una amazona inscrito en un vaso de Cumas (que representa las amazonas contra Teseo); la hija de Príamo y Hécuba, personaje que aquí nos ocupa ${ }^{4}$. Será Virgilio quien bautice a las dos heroínas de una manera definitiva para la posteridad.

Tal vez la aparición del nombre de la mujer y la importancia que ésta va cobrando en el mito literario tenga que ver con la situación del sexo femenino en el mundo helenístico y, posteriormente, en el mundo romano. La mujer adquiere una posición más relevante, en todo caso, que en épocas anteriores $^{5}$. El contexto histórico es importante e influye claramente en el mito. La situación de la mujer mejora considerablemente en el mundo helenístico y romano: al menos los textos virgilianos tienen más consideración con las heroínas.

Las versiones canónicas de las historias de estas dos heroínas - resumidas muy brevemente al inicio de estas páginas - se corresponden con los retratos realizados por Virgilio. Debemos, por tanto, mirar hacia el mundo heleno anterior al legado virgiliano para saber algo más de ellas.

El personaje de Eurídice responde a una creación del mito literario. La mujer de Orfeo, sin citar, aparece aludida en la literatura griega en Alcestis 357-364 de Eurípides, aunque para saber su nombre tenemos que esperar hasta el siglo IV, cuando los testimonios iconográficos (algunos vasos apúlicos de la Magna Grecia y el bajorrelieve ático que representa a Orfeo, Eurídice y Hermes) y literarios (De incredibilibus 21, del mitógrafo PseudoHeráclito) nos lo ofrecen. Hermesianacte nos dice que es tracia, pero la denomina Argíope. El anónimo autor del Epitaphius Bionis recupera su antiguo nombre, pero no dice nada más de ella. Por lo tanto, es un personaje

4 J. Ilberg, «Kreusa», en Lexikon der Griechischen und Römischen Mythologie, vol. II. 1, W. H. Roscher (ed.), Leipzig 1890-1894, coll. 1425-1429. Estos mismos personajes son los que aparecen s. $u$. «Kreusa», a cargo de Kock, en Pauly-Wissowa-Kroll, RE vol. XI. 2, Stuttgart, 1922, coll. 1824-1826. P. Grimal, en su Diccionario de mitología griega y romana (trad. cast., Barcelona, 1981, página 118), recoge estos mismos personajes excepto la amazona. V. en estos manuales las citas literarias donde se pueden encontrar las referencias.

5 Esto nos lo confirma S. B. Pomeroy, Diosas, rameras, esposas y esclavas, trad. cast., Madrid 1987, pp. 141-142. 
sin historia y solamente es conocida por ser la mujer del vate tracio. En el mito primigenio, Orfeo era conocido por traer muertos al mundo de la luz y, con posterioridad, la literatura vinculó su viaje al Hades con la búsqueda de su mujer, a la que el héroe rescataría. Será Virgilio quien modifique el mito y nos cuente algo más de ella: por lo menos nos dice que es una moritura puella, una muchacha destinada a morir ${ }^{6}$.

Creúsa parece tener un poco más de historia al estar vinculada al ciclo mítico troyano y, sin embargo, no aparece en Ilíada ni en los poemas de la caída de Troya. Es una de las princesas de Ilión y las diferentes versiones discuten su situación después de la caída de la ciudad. En los grandes cuadros históricos de Lesque en Delfos, Polignoto la representaba entre las troyanas cautivas. Sin embargo, se creía que había logrado escapar al ser arrasada Troya.

Lo que nadie puede negar es que, a partir de las versiones virgilianas, las dos heroínas cobran entidad propia y, al menos en la literatura, aparecen más citadas y se les presta una mayor atención.

Pues bien, parece que los nombres de estas dos heroínas coincidían. Pausanias señala que existe una tradición que decía que Creúsa, nombre de la esposa de Eneas en Eneida, también era conocida en la antigüedad como Eurídice $^{7}$, según refieren los lesques anteriormente referidos y los Cantos Ciprios (fr. 22 Allen). Pausanias se queda estupefacto porque Virgilio ha impuesto el nombre de Creúsa y éste se ha quedado asentado para la posteridad. Creúsa es una denominación romana, ya que en la tradición griega la heroína era conocida como Eurídice.

Virgilio, que sin duda conocía este dato, lo aprovecha para identificar y relacionar las dos historias y, en concreto, a las dos heroínas. Llega incluso a modificar e innovar en el tratamiento de los dos mitos para acercarlos. Vamos a verlo y comenzaremos haciendo algunas alusiones a sus maridos.

En la antigüedad griega, era de sobra conocido que Orfeo había logrado descender a los infiernos e indagar en los misterios del mundo paralelo. Del mismo modo que el héroe tracio holla el terreno de la muerte, Virgilio hará

6 V. R. González Delgado, El mito de Orfeo y Eurídice en la literatura grecolatina hasta época medieval, Oviedo, 2001, pp. 232-244.

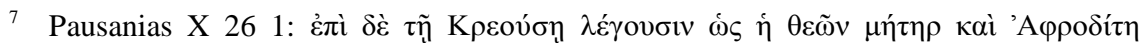

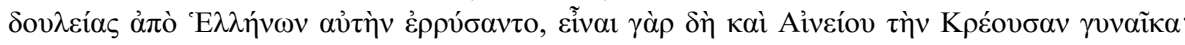

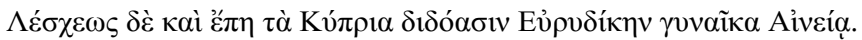


a Eneas descender a los infiernos. El poeta sabe muy bien que no es una historia real y que responde, en todo caso, a una aventura épica más, al modo de las catábasis que aparecían en la literatura griega. Se ha señalado que el descenso de Eneas al Hades es un auténtico gozne en el que giran las dos partes de la obra. Si hasta entonces era un héroe indeciso, sin personalidad, iactatus, al mostrarle su padre en el Más Allá la grandeza del pueblo romano, sale como un héroe nuevo, transfigurado. La historia de Roma, que es la única parte real en la Eneida, es contada a Eneas, héroe legendario, por su padre, un muerto que ha alcanzado la eternidad, en un viaje que el primero realiza al Más Allá y que acaso no fuera más que un sueño (VI 893 y ss.). Parece que ha vuelto de un viaje iniciático ${ }^{8}$ ya que, a partir de la entrevista con su padre y de la contemplación de los futuros héroes romanos, sale fortalecido, lleno de confianza y de seguridad en su misión. En Eneida este episodio no es un relato más: es una configuración de una misión, la configuración de la historia, de carácter religioso, de todo un pueblo. El descenso a los infiernos de Eneas combina pintoresquismo y metafísica, alusiones al pasado de Troya y al futuro de Roma y sus hombres. Debemos señalar que el libro VI es, por su contenido, el más romano de los primeros libros de Eneida. Parece que la inclusión del motivo temático del descensus ad inferos en la literatura va restando interés a la importancia religiosa que este tema tenía en Grecia, al menos en el estadio mítico más primitivo. En el mundo romano, religión y mitología no son equiparables y el viaje al Más Allá se convierte literariamente en una aventura más que el héroe ha de soportar. Prueba de este carácter aventurero son las enigmáticas palabras que la Sibila le dice a Eneas antes de su catábasis, pues le transmiten más información sobre sus enemigos en Italia que las revelaciones de su padre Anquises.

Un rasgo que comparten Orfeo y Eneas es que ambos descienden a los infiernos sin hacer uso de la fuerza, como también había hecho Pólux. Si el primero lo logra por amor conyugal, el segundo será por amor filial, junto al tercero, que responde a un motivo fraternal. Entre los dos héroes virgilianos se establecen, además, paralelismos y coincidencias manifiestas: no solamente el viaje al Más Allá, sino también la búsqueda de la mujer, los hechos parecidos que les ocurren en la historia, la homonimia que antiguamente

8 En Aen. VI se alude constantemente al sueño y a la muerte, al profundo parentesco entre ambos y a la muerte en sueños que facilita un camino por las sombras seguido de un renacimiento. 
hubo entre sus esposas, el tono elegíaco que se respira en los relatos ... Con toda seguridad, los dos pasajes virgilianos fueron compuestos en el mismo año, produciéndose un acercamiento del personaje de Eneas al de Orfeo ${ }^{9}$.

Virgilio tiene en mente la identificación de los dos héroes míticos. También, según Pausanias, aparece Orfeo en una pintura situado junto a Patroclo, sentado y sujetando una lira en su mano izquierda, mientras en la derecha tiene una ramita de sauce ${ }^{10}$, como Eneas en Aen. VI 406, apoyado en el árbol de Perséfone.

Por otra parte, debemos hacer mención, aunque no sea griega, a la heroína por excelencia de Eneida: Dido. El desarrollo de los amores de Dido y Eneas termina siendo trágico - del mismo modo que los amores de Orfeo y Eurídice en Georg. - y proyecta sobre la obra la atmósfera de una tragedia de Eurípides. Ambas mujeres, como también Creúsa, terminan pereciendo por culpa de su amante. El tema del amor y la muerte era muy del gusto de los escritores alejandrinos, así como de los romanos que siguen sus preceptos estéticos. A Virgilio le resulta fácil conciliar en una obra géneros literarios dispares (tal vez porque poéticamente sigue una estética helenística).

Pero lo que aquí nos interesa es ver las relaciones que Virgilio establece entre las mujeres de Orfeo y Eneas. Respecto a la homonimia de la que ya habíamos hablado, debemos señalar un dato importante para Virgilio. La mujer de Eneas era denominada Eurídice por uno de los poetas arcaicos romanos, Ennio ${ }^{11}$. Ambos nombres, Eurídice y Creúsa, significan "la que gobierna". Virgilio no podía denominar a la mujer de Eneas según la antigua tradición romana - es decir, como aparece en Ennio -, porque este nombre traería a sus lectores la imagen de la ninfa que Orfeo pierde en el libro IV de sus Georg. y que en Italia, por lo menos en el Sur, era de sobra conocido por las representaciones órficas de los vasos apúlicos (s. IV a.C.), además de

9 Estos puntos en común han sido estudiados por L. Bocciolini Palagi en «Enea come Orfeo», Maia 42.2, 1990, pp. 133-150.

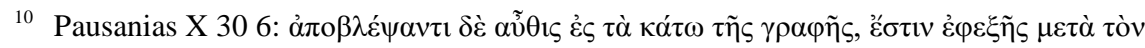

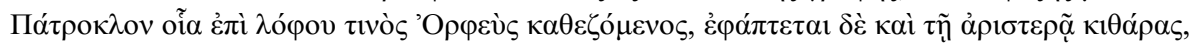

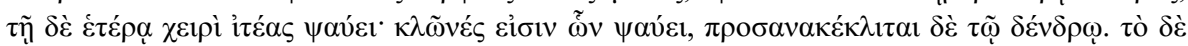

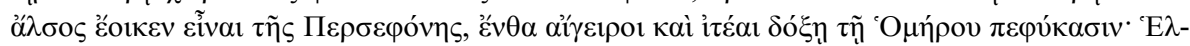

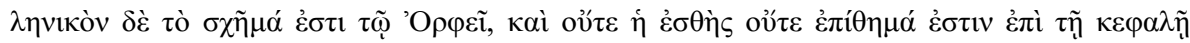

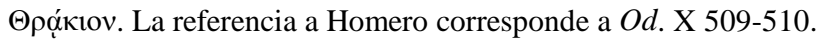

11 Annales I 61-63: Talia tum memorat lacrimans, exterrita somno: | Eurydica prognata, pater quam noster amauit, | Vires uitaque corpus meum nunc deserit omne. 
ofrecer también su nombre un lamento fúnebre en honor a un poeta siciliano

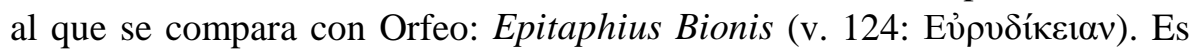
Virgilio quien asienta para la tradición el nombre de la mujer de Eneas ya que, posteriormente, el nombre de Creúsa aparece en Tito Livio ${ }^{12}$, Dionisio de Halicarnaso ${ }^{13}$, Higino o Apolodoro ${ }^{14}$.

La antigua homonimia ha influido en la construcción literaria que Virgilio hace de estas dos figuras míticas. Recordemos que el mantuano estaba embarcado en su obra épica cuando cambia el final de Geórgicas: la inserción del episodio de Orfeo en Georg. data del año $26^{15}$ y en el 24 o 23 a.C. Virgilio lleva a Augusto tres cantos de Aen. entre ellos el segundo. Pues bien, en el final de este libro se narra la salida de Eneas de Troya.

En las dos historias, Virgilio hace un tratamiento de las heroínas que difiere con la tradición que le viene desde antiguo. Eurídice, la mujer de Orfeo, no tenía entidad en la literatura griega anterior. El poeta de Mantua hace a la mujer perecer por una picadura de serpiente y forja su historia en los infiernos. El héroe tracio tiene que superar la prueba que le imponen los dioses para poder recuperarla: no mirar hacia atrás. Pero el héroe se vuelve y

12 I 3.2: hicine fuerit Ascanius an maior quam hic, Creusa matre Ilio incolumi natus comesque inde paternae fugae, quem Iulum eundem Iulia gens auctorem nominis sui nuncupat.

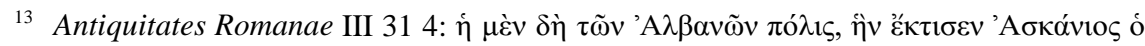

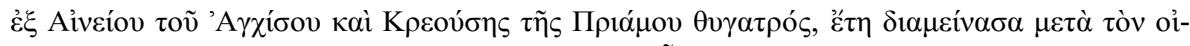

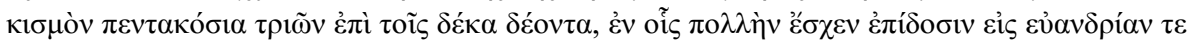

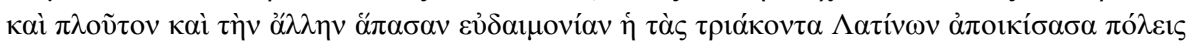

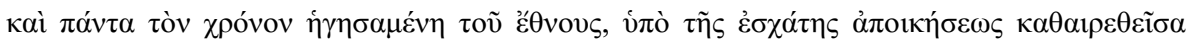

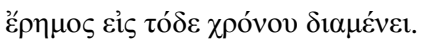

14 Higino 90; Apolodoro III 12 5; encontramos el nombre de la heroína en la enumeración que se hace de los hijos e hijas de Príamo (va situada en último lugar).

15 Sobre la problemática de las Laudes Galli han corrido muchos ríos de tinta. Todo surge cuando Servio, a la hora de hacer sus comentarios a Virgilio (en concreto al referirse al carmen X de Ecl. y al libro IV de Georg.), señala que en el lugar que ocupa la historia de Aristeo había anteriormente un elogio a Galo que Virgilio suprimió por orden de Augusto. Nosotros somos partidarios de la veracidad del testimonio de Servio: v. R. González Delgado, ob. cit. (2001), pp. 218-227. Sobre este asunto puede verse la completa bibliografía que cita P. Domenicucci en la nota primera de su estudio «L'elegia di Orfeo nel IV libro delle 'Georgiche'», Giornale Italiano di Filologia 16, 1985, pp. 239-248. La mayoría de los estudiosos son partidarios de la existencia de dos ediciones antiguas para Georg., aunque hay otros que niegan el valor de las palabras de Servio con argumentos no decisivos. También está el grupo de indecisos que no abogan por ninguna de las dos posturas. 
la pierde para siempre, no sin antes mostrarnos un pequeño y trágico diálogo entre los personajes y a un Orfeo desconsolado que quiere apresar a su amada y no puede. El dramatismo que adquiere esta historia en el legado virgiliano es innegable.

Con Creúsa sucede algo parecido. La historia mítica anterior de esta mujer nos decía que permanecía en Troya y que después moría. Sin embargo, para dar también un mayor efecto dramático a la historia, Virgilio hace que Eneas se vuelva a Troya para recuperarla. Allí solamente encuentra su sombra, a la que intenta apresar y no puede: su mujer ya está muerta.

Ciertamente, Virgilio no sólo modificó las dos historias, sino que las acercó. El hacer que Eneas vuelva a Troya en busca de su esposa se corresponde simbólicamente con Orfeo descendiendo a los infiernos también en busca de su mujer. Los paralelismos que se producen en la narración de estos episodios parecidos son una buena prueba de ello. Estamos ante lo que se ha llamado "arte alusiva" o, más bien, ejemplos de "intertextualidad" o de "referencias internas" ${ }^{16}$. El poeta de Mantua ha identificado y hecho confluir las dos historias, como vamos a ver a continuación.

Si situamos a los dos héroes en su contexto, Orfeo en los infiernos y Eneas en Troya, vemos que ambos quieren salir de allí en compañía de su esposa (la forma coniunx aparece en Georg. IV 456; 465; 504 y en Aen. II $725 ; 777$ ), que les precede (pone sequens en Georg. IV 487 y pone subit en Aen. II 725). Cuando están a punto de lograr la salida (superas ueniebat ad auras en Georg. IV 486 e Iamque propinquabam portis en Aen. II 730), en su distracción (dementia en Georg. IV 488 y male numen amicum en Aen. II 735), el marido mira hacia atrás (la forma verbal respicio en tema de perfecto en Georg. IV 491 y en Aen. II 741) y se da cuenta de que ha perdido a su esposa, censurándose por ello (Quis tantus furor en Georg. IV 495 y quid tantum insano iuuat indulgere dolor en Aen. II 776). Intentarán apresar a

16 Respecto a las relaciones intertextuales, la denominación "arte alusiva" pertenece al campo de la Filología Clásica, sobre todo a partir de Pasquali; actualmente la crítica literaria prefiere el término "intertextualidad" (G. Genette). D. Fowler realiza precisiones teóricas interesantes sobre "alusión" e "intertextualidad" en «On the shoulders of Giants: intertextuality and Classical Studies», Materiali e Discusioni per l'analisi dei testi classici 39, 1997, pp. 13-34. Por "referencias internas" traducimos el término (self-reference) que emplea, para referirse en la obra de Virgilio a casos como el que aquí vamos a comentar, R. F. Thomas en «Virgil's Georgics and the Art of Reference», Harvard Studies in Classical Philology 90, 1986, pp. 171-198 [= en Virgil. Critical assessments of classical authors, vol. II, P. Hardie (ed.), Londres-Nueva York, 1999, pp. 58-82]. 
una mujer convertida en fantasma (umbras en Georg. IV 501 y simulacrum e imago en Aen. II 772 y II 773; 793 respectivamente), pero sus esfuerzos serán en vano (presantem nequiquam en Georg. IV 501 y ter conatus ibi collo dare bracchia cirum en Aen. II 792), pues desaparece como humo en el aire (ceu fumus in auras... tenuis en Georg. IV 499-500 y tenuisque recessit in auras... par leuibus uentis en Aen. II 791-794), diciendo su último adiós (iamque uale, Georg. IV 497 y Aen. II 789). Los héroes no volverán a verla de nuevo (neque ... praetera uidit en Georg. IV 500-502 y nec post oculis est reddita nostra en Aen. II 740) y sus lamentos se escuchan por todo el espacio que les rodea (Orfeo, al igual que sucede en la historia de Filomela, maestis late loca questibus implet en Georg. IV 515 e impleui clamore uias, maestusque en Aen. II 769).

Vemos que las historias se han construido siguiendo un esquema paralelo. Podríamos estar ante el paso a la literatura escrita de una historia popular que conocería Virgilio por la transmisión oral. Prácticamente todas estas secuencias son novedosas en ambos mitos.

Estos paralelismos en la trama de las historias se corresponden con otros paralelismos léxicos y morfológicos, como hemos acabado de ver. Así, cuando Orfeo, en el infierno, se dispone a salir con su recuperada mujer (Georg. IV 485-486) y Eneas, en otro infierno - la fatídica noche de la destrucción de Troya -, emprende la huida (Aen. II 730-731), nos encontramos con los siguientes pasajes:

$$
\begin{aligned}
& \text { Iamque pedem referens casus euaserat omnis, } \\
& \text { redditaque Eurydice superas ueniebat ad auras }{ }^{17} \quad \text { (Georg. IV 485) } \\
& \text { iamque propinquabam portis omnemque uidebar } \\
& \text { euasisse uiam, subito cum creber ad auris... }{ }^{18} \quad \text { (Aen. II 730) }
\end{aligned}
$$

Los paralelismos que podemos apreciar son evidentes: la forma iamque, el verbo euado con la raíz de perfecto, el adjetivo omnis, la preposición ad, la raíz homófona aur-... Vemos que las alusiones intertextuales entre ambos pasajes son significativas.

También leemos en Aen. II 735-741 unos versos que nos recuerdan el mito de Orfeo y Eurídice (especialmente Georg. IV 488-491), producién-

${ }^{17}$ Las traducciones que ofrecemos son nuestras: "Y ya volviendo sobre sus pasos había escapado de los peligros todos y la recuperada Eurídice volvía al mundo de los vivos".

18 "Y ya me acercaba a las puertas y me parecía que había recorrido todo el camino, cuando de repente a mis oídos un repetido...". 
dose de una forma muy clara la identificación entre Orfeo-Eneas y EurídiceCreúsa. Se trata del momento en que los héroes se dan cuenta de que han perdido a su esposa: Eneas, despistado, mira hacia atrás y ve que su mujer no va en pos de él; Orfeo, desconfiado - y también despistado -, lanza la fatídica mirada hacia atrás:

$$
\begin{aligned}
& \text { hic mihi nescio quod trepido male numen amicum } \\
& \text { confusam eripuit mentem. namque auia cursu } \\
& \text { dum sequor et nota excedo regione uiarum, } \\
& \text { heu misero coniunx fatone erepta Creusa } \\
& \text { substitit, errauitne uia seu lapsa resedit, } \\
& \text { incertum; nec post oculis est reddita nostris. } \\
& \text { nec prius amissam respexi animumque reflexi... }{ }^{19} \\
& \text { cum subita incautum dementia cepit amantem, } \\
& \text { ignoscenda quidem, scirent si ignoscere Manes: } \\
& \text { restitit, Eurydicenque suam iam luce sub ipsa } \\
& \text { immemor heu! vistusque animi respexit... }{ }^{20}
\end{aligned}
$$

(Georg. IV 488-491)

En versos posteriores, la pasión y el sufrimiento aparecen notados en las expresiones más simples (heu non tua en Georg. IV 498). Eneas, en primera persona, nos cuenta su salida de Troya en el transcurso de la cual pierde a su mujer y el desgraciado se siente enloquecer (amens en Aen. II 745) cuando se percata de que Creúsa no está a su lado. Decide volver a la ciudad en su busca, pronunciando y repitiendo su nombre a voces, hasta que se encuentra con su fantasma, semejante al pó $\mu \alpha \alpha$ que señala Platón (Symp. 179 d) cuando hace mención de la catábasis órfica, (Aen. II 768-773):

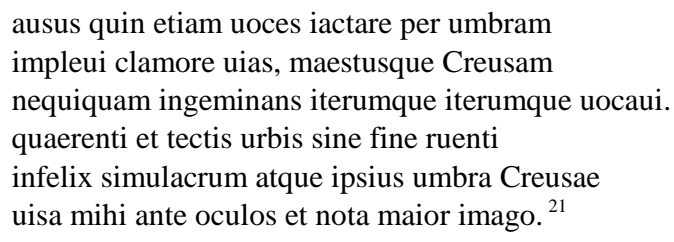

\footnotetext{
19 "Entonces yo no sé qué divinidad enemiga aprovechando mi miedo me privó totalmente de mi confusa razón. Pues, mientras a la carrera avanzo por lugares extraviados y me aparto del lugar conocido del camino, ¡ay! no sé si mi esposa Creúsa se detuvo arrebatada por un desgraciado destino, o se equivocó de camino, o agotada se sentó; desde entonces no fue devuelta a mis miradas. Yo no advertí su pérdida, ni pensé en ella...”.

20 "Cuando una locura repentina se apoderó del imprudente amante, ciertamente perdonable si los Manes supiesen perdonar. Se detuvo y a su Eurídice ya al borde mismo de la luz, olvidándose, ¡ay! y vencido en su espíritu, se volvió a mirarla".

21 "Incluso atreviéndome a dar gritos en la oscuridad, llené con mi chillido las calles y afligido, repitiendo en vano su nombré, llamé a Creúsa una y otra vez. Y mientras la buscaba y recorría sin parar las casas de la ciudad, apareció ante mis ojos un triste fantasma, la sombra
} 
También Orfeo se lamenta de la pérdida de su esposa y repite su nombre a voces constantemente, tanto antes de haber descendido a los infiernos como después de la segunda pérdida de Eurídice. Los versos 770-771 de Aen. tienen referencias evidentes a Georg. IV 514-515, cuando Virgilio realiza la comparación del lamento de Orfeo con los quejidos del ruiseñor (el mito de Filomela), y con los versos 525-526 cuando la cabeza de Orfeo navega Hebro abajo clamando por su esposa y mostrando un héroe enamorado después de haber sido despedazado:

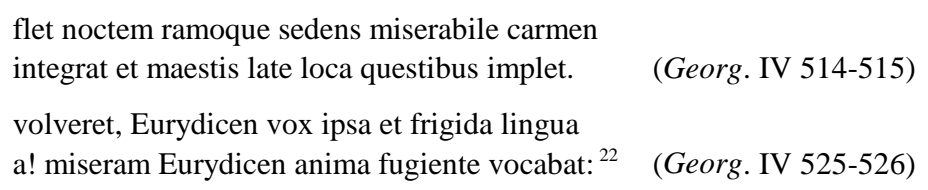

Ese simulacrum que vemos en el verso 772 de Aen., antes de desvanecerse, le dirige unas palabras al esposo, como también Eurídice se las dirige a Orfeo, aunque éstas, en lugar de reproche, resultan ser todo lo contrario: dan ánimos al hombre en la empresa que le habían designado los dioses. Eneas trata en vano de retenerla, como también el vate tracio, y, estilísticamente, las semejanzas que el autor quiere hacer entre las dos historias son más evidentes al utilizar el juego de la triple repetición, como leemos en Georg. cuando Orfeo nombra a su esposa el mismo número de veces o por el terque fragor del verso 493:

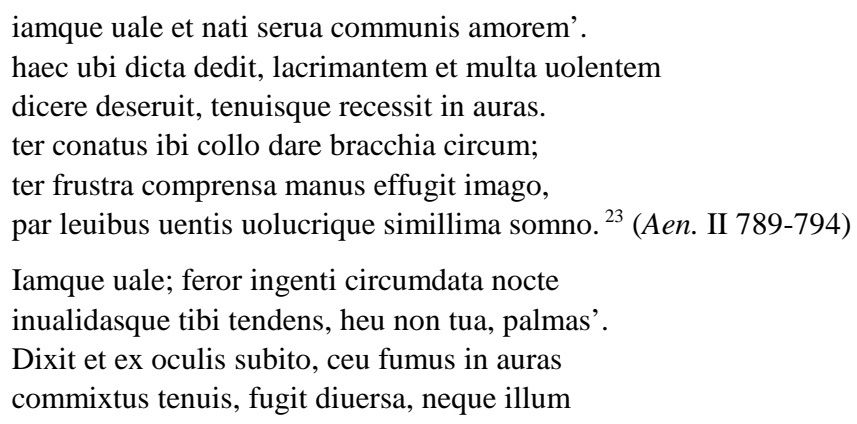

de la misma Creúsa, una aparición más grande que la conocida".

22 "Ella se pasa la noche llorando y, posándose sobre una rama, repite su melancólica canción”; “... volvía, la misma voz y la lengua fría gritaba 'Eurídice, jay, desgraciada Eurídice', escapándosele el alma”.

23 “Adiós ya y guarda cariño a nuestro hijo común'. Dicho esto, me abandonó cuando deshecho en lágrimas deseaba decirle muchas cosas y se desvaneció en los tenues aires. Tres veces intenté rodear su cuello con mis brazos y tres veces, apresada en vano, la sombra huyó de entre mis manos, igual que un ligero viento, como un sueño fugaz". 
presantem nequiquam umbras et multa uolentem dicere praeterea uidit... ${ }^{24}$

(Georg. IV 497-502)

La expresión iamque uale aparece en las dos obras. También la idea de ceu fumus in auras. En el libro II de Aen. leemos tenuisque in auras, pero en V 740 la encontramos literalmente. Vale es una expresión muy utilizada por Virgilio y con un fuerte contenido de tristeza. En su obra lo podemos comprobar en Aen. en el adiós de Creúsa (II 789), en el de Anquises (V 738), en el de Eneas y Palante (XI 98), en el de Camila (XI 827) y, en Bucólicas, en el adiós de Fílide y Menalcas (III 79). Un "adiós" tierno y un silencio que demuestran el amor por el esposo. En Georg. vemos a una Eurídice con mayores rasgos vitales y que incluso evoca unas palabras de reproche a Orfeo, aunque se aparezca ceu fumus in auras ${ }^{25}$.

Además, vuelve a ser semejante - y en la misma posición métrica - et multa volentem dicere ${ }^{26}$. La forma volucer (Aen. II 794) nos lleva al campo semántico de los pájaros y quizá aquí el poeta nos esté haciendo un guiño y tenga en mente la philomela de Georg. IV 511-513, con la intención de mostrarnos el dolor del héroe por la falta de su esposa y unirlo de forma muy sensitiva al amor maternal. Por otra parte, los tres versos que se refieren al dolor aparecen repetidos en las dos obras del poeta de Mantua: Georg. IV 475-477 y Aen. VI 306-308:

$$
\begin{aligned}
& \text { matres atque uiri defunctaque corpora uita } \\
& \text { magnanimum heroum, pueri innuptaeque puellae } \\
& \text { impositique rogis iuuenes ante ora parentum. }{ }^{27}
\end{aligned}
$$

24 “... 'Adiós ya; la inmensa noche me lleva envuelta mientras tiendo hacia ti, ¡ay! sin ser tuya, mis débiles manos'. Dijo, y de repente escapó de su vista en dirección contraria, como el humo impalpable se mezcla con la luz del día, y no vio más al que trataba de apresar sombras en vano y quería decirle muchas cosas".

25 Esta expresión indica que el poeta se estaba inspirando en los poemas homéricos. Así, leemos en Aen. II 791 (tenuisque in auras); V 740 (ceu fumus in auras); IX 236 (ad sidera

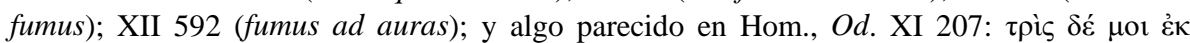

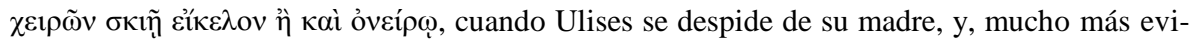

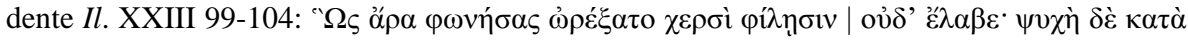

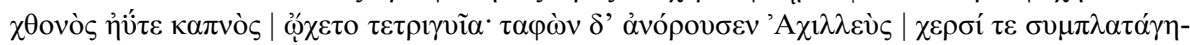

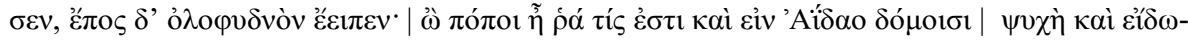

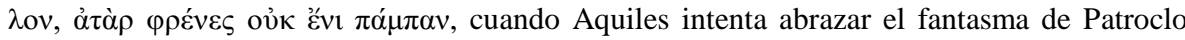
(apreciamos claramente que Virgilio tiene también en cuenta esta lectura para los pasajes del desvanecimiento de Eurídice y Creúsa).

26 Georg. IV 501-502. Esta expresión es semejante a la que el autor utiliza en el episodio de Dido y Eneas (Aen. IV 390-391: et multa parantem | dicere).

27 "Madres y esposos y cuerpos sin vida de magnánimos héroes, niños, doncellas y 
Además, cuando los héroes se dan por vencidos, deciden emprender el camino hacia las montañas y refugiarse en ellas. Virgilio no ofrece en Aen. una composición con visos tan dramáticos como en Georg., pero los recursos que utiliza para mostrar en este pasaje de su obra épica el patetismo son los mismos que vemos en su poema dedicado a la agricultura. Entre esos recursos destaca la repetición del nombre de la mujer, a la que en Aen. consigue destacar mencionándola siempre en los loci praestantes de final de verso (II 562, 597, 651, 666, 738, 769, 772, 778, 784 - véase la concentración de las menciones que de su nombre aparecen en el pasaje que acabamos de analizar-, IX 297). Creemos que Virgilio en Georg. está anticipando el desenlace del episodio de Dido y Eneas ${ }^{28}$. Ambos héroes pierden a su amada y son víctimas de Amor. Dido y Eurídice son unas moriturae puellae y están destinadas, lo quieran o no, a morir ${ }^{29}$.

jóvenes colocados en la hoguera ante los ojos de sus padres". Un breve comentario a estos versos podemos leerlo en las pp. 5-6 de G. Lee, «Imitation and the Poetry of Virgil», en Virgil, I. Mc Auslan \& P. Walcot (ed.), Nueva York, 1990, pp. 1-13, en donde se destaca el patetismo de la escena, la relación que en la sociedad de la época esta imagen podía tener con

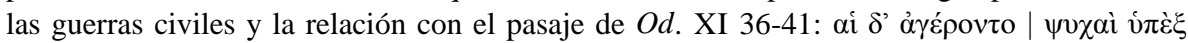

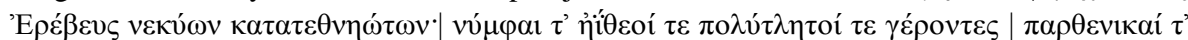

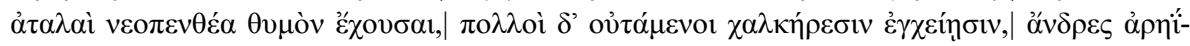

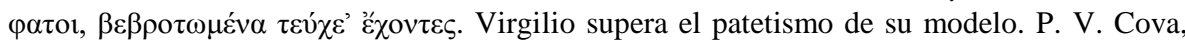
«Arte allusiva in Georg. IV, 471-484", Bolletino di Studi Latini 3, 1973, pp. 281-303, va más allá y señala que los versos 471-484 fueron compuestos para Aen. y, después, busca una explicación - no muy convincente para nosotros - de porqué Virgilio los traspasó a Georg. La interpretación que ofrece de la catábasis de Eneas es muy curiosa (p. 302): «il vero motivo della catabasi di Enea non è la celebrazione di Augusto o la gloria di Roma, ma la tragica inchiesta dell'uomo sul male e sul dolore. Non il proemio del libro III, ma l'episodio di Orfeo diventa così nelle Georgiche la promessa e insieme l'interpretazione autentice dell'Eneide».

28 V., por ejemplo, la nota anterior. G. Barra en «La figura di Orfeo nel IV libro delle Georgiche», Vichiana 4.3, 1975, pp. 193-199 ya señala que: «L'episodio di Orfeo anticipa, in certo modo, quello di Didone, la quale crede, col falso nome di coniugio, di coprire la sua colpa» (p. 199). J. Heurgon ya se dio cuenta de la semejanza entre Creúsa y Eurídice en «Un example peu connu de la retractatio virgilienne», Revue des Études Latines 9, 1931, pp. 258268: «la disparition de Créuse, à la fin du $\mathrm{II}^{\mathrm{e}}$ livre de l'Eneide est une retractation de la disparition d'Eurydice, du IV livre des Géorgiques ... un parallélisme soutenu» (p. 263). También W. W. Briggs en «Eurydice, Venus and Creusa: a note on structure in Virgil», Vergilius 25, 1979, pp. 43-44, señala que Virgilio adapta el pasaje de Georg. en Aen. describiendo las entrevistas de Eneas con Venus y Creúsa. Para este autor, el libro II de Aen. estaría compuesto con posterioridad al epilio de Orfeo y Eurídice de Georg.

${ }^{29}$ La forma moritura aparece en la obra virgiliana referida a Eurídice (Georg. IV 458), a Hero, la trágica amante de Leandro (Georg. III 263), a Dido, en mayor número de veces (Aen. 
Sin embargo, existe una antítesis fundamental: Orfeo ve desvanecerse a Eurídice porque respexit (Georg. IV 490-491); Eneas a Creúsa precisamente porque non respexit (Aen. II 738-741). El primero transgrede el tabú impuesto por los dioses infernales y será castigado. El segundo la perdió por un descuido: si hubiese mirado hacia atrás y hubiese estado pendiente de su esposa, no la habría perdido.

La primitiva homonimia ha inspirado a Virgilio para realizar este duplicado. El poeta mantuano ya debía de conocer la semejanza que presentaban algunas heroínas en la literatura griega ${ }^{30}$. Por tanto, en nuestro caso, a partir de evocadoras imágenes y recursos estilísticos, Virgilio innova en el tratamiento mítico de las dos heroínas, dotándolas de más personalidad e importancia que la que poseían en el mundo griego, y, a la vez, unifica estas figuras míticas, pese a la aparente disparidad de las historias. Son, por tanto, dos heroínas distintas que se miran en un mismo y único espejo, que refleja la imagen de una sola mujer, víctima del amor de su marido: un sutil juego de espejos que ya habría sido apreciado por los lectores latinos.

IV $308 ; 415 ; 519 ; 604$ ), y a la reina Amata, esposa de Latino y madre de Lavinia (Aen. XII $55 ; 602)$.

${ }^{30}$ Este sería el caso, por ejemplo, de la homérica Nausícaa y la Medea de Apolonio de Rodas. V. el estudio de M. Pérez López sobre estas dos heroínas míticas: «Od. 6. 273-315 y A. R. 3.771-801: un ejemplo de intertextualidad» en Actas del X Congreso Español de Estudios Clásicos. Vol. I, Madrid, 2000, pp. 581-588. 